tráfico de drogas es transformado y minimizado por las diferencias subculturales, las redes sociales y la omnipresente economía de la droga.

En los centros de tráfico de drogas situados en la frontera entre México y los Estados Unidos de América, como el formado por Ciudad Juárez y El Paso, el comercio ilegal de narcóticos se refleja en diversos elementos de su cultura expresiva- como la música, la ropa y las joyas- y en la manera en que viven las personas, en sus elegantes automóviles y ostentosas viviendas. Este artículo analiza el proceso de "normalización" del tráfico de drogas a fin de reducir el vacío que sobre este tema existe en la literatura especializada.

La normalidad con que se acepta el tráfico de drogas en la frontera mexicanoestadounidense se debe en parte a que esta es una de las regiones más pobres de los Estados Unidos y a que a lo largo de más de 100 años, esta actividad ha sido un medio práctico y rápido de aumentar los ingresos. Por lo tanto, el tráfico de drogas puede considerarse un medio que les permite a personas relativamente pobres salir de la pobreza y se ha convertido en parte de la identidad propia de muchas comunidades fronterizas.

A pesar de que los medios noticiosos de El Paso han reducido al mínimo la cobertura del narcotráfico, las personas que viven en esas localidades saben que el negocio ilícito de las drogas está a todo su alrededor. Las historias vinculadas con el tráfico de drogas a través de la frontera demuestran que los traficantes, como los drogadictos, "pueden ser víctimas, transgresores, hermanos, hermanas, hijos e hijas".

Las historias y canciones acerca de esta importante actividad económica y cultural forman una especie de cultura folclórica oral. Su representación popular más conocida corresponde a las canciones folclóricas denominadas "corridos", que recientemente han dado origen a los "narcocorridos", que narran las hazañas de famosos narcotraficantes mexicanos.

El folclor cotidiano también consiste en los cuentos "habituales" contados por algún participante, sus amigos o parientes. Dichos cuentos en torno a las drogas - como el folclor en general- benefician al narrador de diferentes formas: elevan su autoestima al permitirle impresionar a sus interlocutores con sus conocimientos y hazañas; ayuda a aligerar la carga de culpa y ansiedad que sufre y lo ayuda a divulgar una información encubierta sobre una actividad clandestina. Por lo general, estas historias tratan temas de iniciación, confesión, enfrentamiento, aleccionamiento $\mathrm{u}$ horror. Con frecuencia comienzan con el detenimiento de los protagonistas por la justicia y continúan con un recuento retrospectivo de los sucesos que condujeron a su captura.
El análisis de las costumbres y del folclor popular de la zona demuestra que para la población de la frontera mexicanoestadounidense, el tráfico de drogas es una actividad tácitamente tolerada o un fenómeno cotidiano que, sin ser totalmente aceptado, no se considera una desviación radical del estilo de vida imperante. Comprender este fenómeno puede ayudar a encaminar los esfuerzos por modificar las políticas contra el narcotráfico y los programas gubernamentales aplicados en la actualidad. (Campbell H. Drug trafficking stories: everyday forms of narco-folklore on the U.S.-Mexico border. Int J Drug Policy. 2005;16(5):326-33).

\section{Mayor respaldo científico para evaluar la eficacia de los programas de salud pública}

La Iniciativa Futuros (Futures Initiative), emprendida por los Centros para el Control y la Prevención de Enfermedades (CDC) de los Estados Unidos de América en 2003, impulsó la búsqueda de datos probatorios para evaluar la eficacia de los programas de salud pública relacionados con la misión de esos centros. Este trabajo evalúa las pruebas científicas publicadas sobre los factores de riesgo modificables y las intervenciones relacionados con las enfermedades que constituyen una mayor carga para la salud pública de los Estados Unidos y que son objeto de atención de los programas financiados por los CDC.

Se utilizaron ocho medidas de la carga de enfermedad, lesión y discapacidad (mortalidad, años de vida perdidos antes de los 75 años de edad, años de vida ajustados por discapacidad, causas de muerte, número de hospitalizaciones, días de hospitalización, casos de discapacidad y costos médicos directos) aportada por 20 enfermedades o combinaciones de enfermedades.

Se revisaron los trabajos publicados en PubMed, Morbidity and Mortality Weekly Report y el sitio en Internet de la Colaboración Cochrane. Se buscó información sobre los factores de riesgo modificables, la fracción atribuible (FA) o el porcentaje de riesgo atribuible poblacional (FAp), las intervenciones poblacionales dirigidas a la prevención primaria o secundaria de cada una de las enfermedades analizadas y la fracción prevenible (FPp).

En total se encontraron 682 publicaciones - de ellas 34 revisiones sistemáticas-, en las que se identificaron 194 factores de riesgo modificables asociados con las 31 enfermedades de mayor impacto sobre la salud que eran objeto de estudio de los CDC. Se identificaron 703 intervenciones de salud pública poblacionales relacionadas con $28(90,3 \%)$ de las 31 enfermedades estudiadas y con $139(71,6 \%)$ de los 194 factores de riesgo encontrados. Se halla- 
ron 75 factores de riesgo con cuatro intervenciones o más. Algunas intervenciones estaban dirigidas a más de una enfermedad, pero no se encontraron intervenciones dirigidas contra tres $(9,7 \%)$ de las enfermedades estudiadas (artritis, cáncer de próstata y pérdida de la audición).

No se encontraron pruebas científicas suficientes para poder evaluar la eficacia de las intervenciones diseñadas para reducir el riesgo de las principales causas de enfermedad, lesión y discapacidad.

Estos resultados subrayan la necesidad de investigar la eficacia de intervenciones poblacionales específicas y de realizar revisiones sistemáticas a fin de reunir pruebas científicas que demuestren su utilidad en relación con enfermedades importantes para la salud pública.

¿Cuál sería, entonces, la agenda para lograr una salud pública basada en pruebas científicas? En primer lugar, se requieren investigaciones básicas que evalúen los diversos indicadores de la carga de enfermedad y que permitan identificar las brechas en los datos acerca del riesgo atribuible. Segundo, se deben investigar las enfermedades y los factores de riesgo modificables para poder identificar las intervenciones basadas en datos probatorios. Tercero, se deben diseñar investigaciones metodológicas que permitan evaluar el efecto de múltiples intervenciones sobre una misma enfermedad y los resultados de una intervención sobre diferentes enfermedades. Por último, se deben evaluar la eficacia, la utilidad y los beneficios de estas intervenciones en función del costo, para decidir cuáles políticas son aplicables en cada nivel del sistema de salud pública.

Los especialistas en salud pública deben hacer frente de una manera más creativa a las complejidades metodológicas que se presentan. Los estudios observacionales o cuasiexperimentales son más prácticos en el contexto de la salud pública que los ensayos aleatorizados y se debe mostrar una mayor flexibilidad en la aplicación de nuevos conocimientos. Para enfrentar estos retos metodológicos, es necesario entrenar a más investigadores en diversas disciplinas relacionadas con la salud pública, entre ellas la epidemiología, las ciencias sociales y conductuales, y la economía. (Thacker SB et al. The evidence base for public health informing policy at the Centers for Disease Control and Prevention. Am J Prev Med. 2005;28(3):227-33).

\section{Importantes aportes al conocimiento del dengue y dengue hemorrágico}

Desde finales de la década de 1970, Cuba ha sido azotada por varias epidemias de dengue. Este artículo representa una crónica de los logros alcanzados por los investigadores del Instituto de Medicina
Tropical Pedro Kourí (IPK), de La Habana, Cuba, a lo largo de más de 20 años. Las investigaciones realizadas por este centro han contribuido notablemente a ampliar el conocimiento actual sobre la patogenia, el diagnóstico, la epidemiología y las manifestaciones clínicas de esta enfermedad.

La primera epidemia de dengue hemorrágico en las Américas se presentó en Cuba en 1981 con más de 344000 casos; de ellos, unos 10000 se consideraron graves o muy graves. Esta epidemia, causada por el virus del dengue tipo 2, provocó 158 muertes, 101 de ellas en niños. El dengue hemorrágico es la forma más letal de dengue y antes de 1981 solo se habían informado 60 casos en toda la Región.

Las investigaciones realizadas en el IPK a partir de ese momento condujeron a importantes conocimientos epidemiológicos, virológicos y clínicos. En primer lugar, el estudio de las tres epidemias de dengue hemorrágico que han afectado a Cuba (en 1981, 1997 y 2001-2002) ha confirmado que la infección secundaria es grave en más de $97 \%$ de los casos.

Contrario a lo que se pensaba con anterioridad, estos estudios han demostrado que los casos graves pueden ocurrir aun habiendo transcurrido varias décadas entre la infección inicial por el virus del dengue tipo 1 y la infección secundaria por el virus tipo 2. Eso significa que una vacuna realmente eficaz debe proteger contra los cuatro serotipos de dengue a largo plazo, ya que de lo contrario, la propia vacuna podría sensibilizar a los vacunados y provocar dengue hemorrágico grave ante una infección secundaria por un serotipo diferente.

Con relación a los factores de riesgo de las formas graves de dengue, se demostró que las personas con enfermedades crónicas - como asma bronquial, diabetes mellitus y drepanocitosis - tienen una mayor probabilidad de contraer el dengue hemorrágico. Un aporte novedoso es que la forma hemorrágica se ha observado en Cuba predominantemente en personas de la raza blanca. La edad entre los 3 y 14 años también es un factor de riesgo.

Las investigaciones realizadas por este grupo también demostraron que el virus asociado con las epidemias de dengue hemorrágico en Cuba pertenece a un genotipo asiático, y documentaron la presencia de un patrón evolutivo en algunos genes. También han encontrado un alto grado de conservación en los genes que codifican proteínas estructurales y en la secuencia de las regiones no codificantes del genoma vírico.

Datos preliminares han demostrado que la presencia de anticuerpos producidos contra un serotipo de dengue diferente del que provoca la infección ayuda a reducir la gravedad de la enfermedad. Estos anticuerpos desaparecen con el tiempo, lo que puede explicar por qué las infecciones secundarias producen con frecuencia casos más graves que la 